\title{
Kámûs-ı Fârsî’nin Türkçe kaynak metin olarak kelime hazinesine katkısı
}

\section{Yasin YAYLA1}

\begin{abstract}
APA: Yayla, Y. (2019). Kámûs-ı Fârsînin Türkçe kaynak metin olarak kelime hazinesine katkısı.
\end{abstract} RumeliDE Dil ve Edebiyat Araşttrmaları Dergisi, (Ö5), 77-82. DOI: 10.29000/rumelide.606071.

\section{$\ddot{\mathbf{O} z}$}

Okuma, konuşma, dinleme ve yazmadan oluşan dört temel dil becerisini gerçekleştirmede zengin bir kelime hazinesine sahip olmak son derece mühimdir. Türkiye Türkçesinin kelime hazinesini zenginleştirmek için akraba dillerden faydalanılabileceği gibi, bir zamanlar yazı dili olarak kullanılan Osmanlı Türkçesinden de faydalanılabilir. Bu faydalanma, dilin bütün hususiyetlerini barındıran, kültür taşıycılığı yaparak bugünkü dile kaynaklık eden eserlerin taranarak üzerlerinde çalışılması ile yapılabilir. Bu düşüncelerle bu çalışmada, müellifi belli olmayan ve 20. yüzyılın başlarında yazıldığı tespit edilen Kámûs-ı Fârsî adlı Farsça-Osmanlı Türkçesi sözlükten bugünkü Türkçe Sözlük'e eklenerek katkı sağlayacak otuz üç tane kelime manaları ile birlikte listelenmiştir.

Anahtar kelimeler: Türkiye Türkçesi, Osmanlı Türkçesi, Türkçe eğitimi, kelime hazinesi, sözlük.

\section{The contribution of Kámûs-ı Fârsî to the vocabulary as Turkish source text}

\begin{abstract}
It is extremely important to have a rich vocabulary to perform the four basic language skills of reading, speaking, listening and writing. In order to enrich the vocabulary of Turkish Turkic, it is possible to make use of related languages, as well as the Ottoman Turkic language, which had been once used as a writing language. This utilization can be done by scanning the works originating present language by studying the language that carries all the characteristics of the language, carries culture. With this in mind, in this study, the Persian-Ottoman Turkic dictionary named Kámûs-ı Fârsî, which was written in the beginning of the 2oth century, has been scanned and thirty-three words, which can be contributed to present Turkish Dictionary have been listed with their meanings.
\end{abstract}

Keywords: Turkish, Ottoman Turkish, Turkish education, vocabulary, dictionary.

\section{Giriş}

Dil, insana bahşedilmiş bir nimettir. İnsan, kullandığı dil ile düşündüklerini ifade eder ve ifade ettikleri sayesinde başkaları ile anlaşır, cemiyet içinde de anlaştığı kadar söz sahibi olur. Bir an için duygu ve düşüncelerimizi ifade ettiğimiz dilin olmadığını düşünelim. Herhâlde anlatmak istediklerimizi anlatmak için onları sırtlayıp getirmek mecburiyetinde kalırdık. İşte böyle bir nimet olan ve insana büyük kolaylıklar sağlayan dili, kurallarına uygun olarak öğrenme ve öğretme de ancak dil dersleri vasıtasıyla yapılabilir.

Dört temel dil becerisi vardır: okuma, konuşma, yazma, dinleme. Bu becerileri en üst seviyede sağlayabilmek için insanın ihtiyacı olan cevher muazzam bir kelime hazinesidir. Dilbilimcilere göre

$1 \quad$ Dr. Öğr. Üyesi, Kırklareli Üniversitesi Fen Edebiyat Fakültesi, Türk Dili ve Edebiyatı Bölümü, (Kırklareli, Türkiye), yyasinyayla@gmail.com, ORCID ID: oooo-ooo1-5726-884X [Makale kayıt tarihi: 12.06.2019-kabul tarihi: 18.08.2019; DOI: $10.29000 /$ rumelide.606071] 
kelime "gösteren" ise kavram "gösterilen"dir. Kavramların göstereni olarak kelimeler, insanların mana dünyasını biçimlendiren vazgeçilmez unsurlardır (YILDIZ, OKUR, vd. 2008: 31). Çocuklar dünyayı, bildiği kelime sayısı kadar bilir (YILDIZ, OKUR, vd. 2008: 311). Tabii ki bu, sadece çocuklar için geçerli değildir. Bir yabancı dili öğrenirken o dilden ne kadar kelime öğrenirsek dile o kadar hâkim olabiliriz ve kendimizi ancak o kadar ifade edebiliriz. Yabancı dilde hâl böyle iken ana dil için de aynı durum tabii olarak geçerlidir.

İnsanın kelime ve kavram yönünden zengin bir birikime sahip olması düşüncede de zengin olmasını sağlar (ÖZBAY ve MELANLIOĞLU 2008: 31). Bu zenginlik kendimizi doğru ifade etmemizi, kurduğumuz cümlelerin ardından "yani” ile başlayan açıklamalar yapma mecburiyetimizi de ortadan kaldırır.

Günümüzde dünyadaki her alanda olduğu gibi dilde de hızlı bir değişme yaşanmaktadır. Bu değişme "gelişme" midir, "gerileme" midir ya da "yok olma"ya doğru bir gidiş midir? İnsanların kendilerini hâlihazırda bulunan kelimelerle ifade edemeyişleri ya da birbirinden farklı birçok mana için tek bir kelimeyi kullanmak mecburiyetinde kalıyor olmaları -herkesin hak vereceği gibi- büyük bir meseledir. Mesela "Sana önerim bu." derken acaba bu cümleyi kullanan kişi muhatabına bir "tavsiye"de mi bulunmaktadır yoksa bir şey mi "teklif" etmektedir? "Seni uyarıyorum" diyen bir kişi acaba muhatabını "ikaz” mı etmektedir yoksa kastettiği şey “ihtar” mıdır? "Bu dereceye kadar düştün mü?” acaba doğru bir cümle midir? Dereceye düşülür mü çıkılır mı? Çıkmak için "derece”yi kullanıyorsak düşmek için neyi kullanmalıyız? Bir kişi "düş” kelimesini hem 'rüya' manasında "Seni düşümde gördüm." diye kullanıyorsa ve hem de 'hayal etmek' manasında "Bir düşlesene." diyebiliyorsa burada bir mana karışıklığı, bir mesele yok mudur? Örnekleri çoğaltabileceğimiz bu durumların hepsi muhakkak ki birer meseledir. $\mathrm{Bu}$ meselelerin niçin oluştuğu ile ilgili tartışllı sayfalarca kitap yazılabilir; fakat bu meselelerin niçin meydana geldiği mühim olmakla birlikte nasıl çözüleceği daha mühimdir.

Türkçe; Kâşgar'dan Saraybosna'ya, Moğolistan'dan Arabistan'a kadar geniş bir coğrafyada kullanılmaktadır. Türkçe, bu geniş coğrafyaya Türkçe konuşanların hâkim olması ve hizmet götürmesi ile yayılmıştır. Bu coğrafyalardaki hâkim unsur olan Türk devletlerinin çekilmesi ile birlikte birçok devlet oluşmuş, Türkçe konuşan insanlar birbirinden uzaklaşmış, farklı coğrafyalarda farklı devletler kurmuşlar ya da farklı devletlerin içinde azınlık olarak yaşamışlar ve yaşamaktadırlar. Bu kopuş ve ayrılış dilde de bir kopma ve ayrılmayı beraberinde getirmiştir. Bugün Türkiye Cumhuriyetinin resmî dili olan "Türkiye Türkçesi” de bu yaprak dökümünden "nasibini” almıştır. "Türkçe” için dökülen yaprakları eskisi gibi yeşertmek mümkün olmasa da Türkçe ile uğraşanlara düşen vazife, sararmakta olan yaprakları yeşertmek ya da hâlihazırda bulunan yaprakların dökülmesini engellemek olmalıdır. Bunun için de hastaya kuvvetlenmesi için yapılan "aş" gibi dile de "aşı" yapmak gerekmektedir. Bu "aşı", akraba Türk dillerinden ithal edilebileceği gibi altı yüz yılı aşkın bir süre yaşamış ve bu ömrü boyunca her alanda dünya mirasına katkı sağlamış olan Osmanlı Devleti [1300-1922]'nin yazı dili olarak kullanılan "Osmanlı Türkçesi”"nden de yerli olarak üretilebilir. "Aşı”dan kasıt "kaynak metinler"dir. Kaynak metinler, ait olduğu cemiyetin kültürü ve dili ile ilgili hususiyetleri içinde barındıran eserlerdir.

Sözlükler sadece kelimelerin yanlış doğru cetveli gibi manalarını veren bir dizin değildir. Bir dilin işlenmişliğinin örneği, zenginliğinin göstergesi, tarihî süreç içinde yaşanmışlığının belgesi, iki kapağı arasında bulundurduğu kelimelerle âdeta geçmişten bugüne çekilmiş bir film şerididir ve bu özellikleri hasebiyle birer kaynak metindir.

Geçmişi bugün tekrar yaşamak mümkün değildir; fakat bugün yaşanan hayat, geçmişten kalan kültür birikiminin devamıdır ve bu kültür birikimine bugünden uzanmak gerekmektedir. Türk dilinin 
kaynaklarından olan sözlükleri ve onları vücuda getirenleri tanıtmak, geçmişte kalanları geçmişte bırakmayarak bugüne kazandırmak Türkçe öğretme işiyle uğraşanların vazifesidir.

Bu düşüncelerle bu çalışmada Türk Dil Kurumu Kütüphanesine Etüt 8o/1 numarası ile kayıtlı cilt ve Etüt 93/1-2 numaraları ile kayıtlı cüzlerden mürekkep, müellifi bilinmeyen ve yirminci yüzyılın başında yazıldığı tespit edilen Kámûs-ı Fârsî adlı Farsça-Osmanlı Türkçesi lügat üzerine yapılan çalışma neticesinde bugünkü Türkçe Sözlük'e girerek Türkçenin kelime hazinesine katkı sağlayabilecek otuz üç kelime listelenmiştir.

\section{Kelimeler}

Kámûs-ı Fârsî üzerine yapılan çalışma neticesinde bazıları Osmanlı Türkçesi sahasına giren ve Türkiye Türkçesine geçişte eriyen, bazıları bugünkü Tarama Sözlüğü ve Derleme Sözlüğü sahasına giren ve bu sözlüklerde bulunan fakat Türkçe Sözlük'te bulunması gerektiği hâlde bulunmayan birçok kelime tespit edilmiştir. Bu kelimelerden otuz üç tanesi abece sırasına göre aşağıda listelenmiştir. Taranan sözlük Farsça madde başlarına karşılık Türkçe izahlardan oluşmaktadır. Aşağıdaki listede koyu karakterlerle yazılan kelimeler Farsça madde başına karşılık verilen Türkçe izahlardan elde edilen ve bugünkü Türkçe Sözlük'e eklenmesi teklif edilen kelimelerdir. Kelimelerin karşısına yine çalışmaya konu olan sözlükteki Farsça madde başına karşılık verilen Türkçe izahları da yazılmış ve kaynak eserdeki cilt ve sayfa numaraları da gösterilmiştir. Asıl madde başı olan Farsça kelimeler ise eğik harflerle ve köşeli parantez içinde koyu yazılmış olan Türkçe madde başının yanında verilmiştir.

1. beg [hurohe]: 'Avcılarıı avı aldatmak için ağıı kenarına bağladıkları hayvan.' (Kámûsıı Fârsî, o9. cüz: 17), 'Kuş avlamak için kullanılan başka kuş.' (DİLçín 1983: 29).

2. böy [āg்nde]: 'Uzun ayaklı bir cins zehirli örümcek, ruteylâ. Bu hayvan Avrupa'nı $\eta$ cenup taraflarında çok bulunur. Sekiz gözü vardır. Sokmasından hasıl olan avarız hakkında bir hayli mübalağalar menkuldür. Hakikatte tehlikeli değildir. Vücudu siyah benekli ve esmer olup karnını $\eta$ altı kırmızıdır. Ortasında beyaz bir çizgisi vardır.' (Kámûs-ı Fârsî, 1. C: 490), 'Zehirli örümcek.' (DİLçìN 1983: 38).

3. çapük [hiş̧tçe]: 'Donuy ağına, gömlek ve entarinin peşine eklenen müsellesü 'ş-şekl bez parçası.' (Kámûs-ı Fârsî, o8. cüz: 80), 'Don ağı.' (DİLçìn 1983: 51).

4. cardın [her-mūş]: 'Bir cins gayet iri fare.' (Kámûs-ı Fârsî, o6. cüz: 100), 'İri sıçan.' (DİLçíN 1983: 45). TIETZE'ye göre kelime Ar. cirdavnden² gelmektedir (TIETZE 1999: 270). Kelimenin Farsçası olan her-mūşun Türkçe karşıllğı ise 'eşek sıçanı'dır. [her < Fa. 'eşek' (STEINGASS 2005: 450 $\mathrm{O}^{\mathrm{b}}$ ) + mūş < Fa. 'sıçan' (STEINGASS 2005: 1345')].

5. egir $[\bar{a} l v a \bar{h} h]$ : 'Ekseriya havuz kenarlarında neşvünema bulan bir nevi devâ'î köktür. Arapça buya vacc dèrler.' (Kámûs-ı Fârsî, I: 490), 'Karın ağrısına kullanılan bir kök, andız.' (DİLÇİN 1983: 78). Kelimenin Arapçası için Kamus Tercemesi'nde şu ifadeler yer almaktadır: vacc < Ar. 'Bir deva adıdır. Türkîde egir dedikleri kök olacaktır.' (FĪRŪZĀBĀDĪ 1268, I: 448).

2 Ar. cirdavn 'field-mouse; rat (tarla faresi; sıçan)' (STEINGASS: The Student’s Arabic-English Dictionary: 1. C, 228'a. s.). 
6. gedeleç [şegā]: 'Kubur, içi boş dar ve uzun ustuvânî kap, ki bir tarafı kapalı olur, içine ok vaz olunur, ok kuburu, tîr-keş, tîr-dân.' (Kámûs-ı Fârsî, 15. cüz: 019), 'Ok kuburu, tirkeş, sadak.' (DİLçì 1983: 90).

7. hacâlet [şerm]: 'Haya, namus, gayret, utanma, mahcubiyet, ar, edep, arz, ismet, pâkdâmenlik, iffet.' (Kámûs-ı Fârsî, 15. cüz: 3). hacil 'kederli, üzgün' (Derleme Sözlüğü 1974, VII: 2248') kelimesi de bu kelime ile bağlantılı olmalıdır.

8. iğtişaş [āşob]: 'Fitne, fesat, kavga, gürültü, ihtilal, karışıllık, kargaşalık, inkılap.' (Kámûs-ı Fârsî, 1. C: 478).

9. istişmâm ètmek [şemīden]: 'koklamak' (Kámûs-ı Fârsî, 16. cüz: 040).

10. ışkırmak [şehliden]: 'Islık çalmak, ağızdan ince ses çıkarmak, izhâr-ı safîr eylemek' (Kámûs-ı Fârsî, 14. cüz: 71), 'to whistle.' (REDHOUSE 1890: 297). işkirtmek 'avı ıslık çalarak yatağından kaldırmak' (Derleme Sözlüğü 1974, VII: 2564a).

11. kayırtmaç [dār-ḩāl]: 'Bir ağaçtan alınıp başka yere gars olunan dal, daldırma.' (Kámûs-ı Fârsî, 10. cüz: 28), 'Bir ağaçtan koparılıp başka bir yere dikilen fidan.' (DİLçíN 1983: 124).

12. kıçı [hefec]: 'Yabani hardal, bir nebât-ı tıbbî.', (Kámûs-ı Fârsî, 07. cüz: 50), 'Tereye benzer bir ot, kekik.' (DİLÇín 1983: 136).

13. kıytık [çeġbet]: 'Döşek, yorgan hırka vesaire gibi şeyleri $\eta$ içine ve arasına konulan yü̈ ve pamuk şeyler, lif.' (Kámûs-ı Fârsî, 02. cüz: 13), 'Kumaş parçaları döküntüsü, kırpıntı.' (Derleme Sözlüğü 1974, VII: 2860).

14. kileçeri [hêrțā]]: 'buğday aralarında neşvünema bulur [bir tane]' (Kámûs-ı Fârsî, o6. cüz: 93), Buğday içinde bulunan siyah taneler (DİLçìs: 1983: 140).

15. koduk [her-kurre]: 'Eşek yavrusunuy küçüğü, küçük sipa.' (Kámûs-ı Fârsî, o6. cüz: 95), 'Sipa.' (DİLÇĩ 1983: 142).

16. kor $[\bar{a} s ̧ k \bar{u} \mid \bar{a} s ̧ k \bar{u} b]$ : 'Duvar sırası.' (Kámûs-ı Fârsî, I: 475), 'Duvar taşlarından bir tek sıra, dizi' (DİLçín 1983: 156).

17. kurumsak [şāh-dār]: 'Deyyus, gözüyle suretâ zevcesi olacağı fezâhatte görüp i‘mâz eyleyen izzetsiz adam.' (Kámûs-ı Fârsî, 13. cüz: 11), 'Pezevenk, deyyus.' (DİLçín 1983: 149).

18. mübâriz [āhenīn-ciger]: 'Demir ciğerli, kahraman, pehlevan, şeci, mert, cesur, kaviyyü 'l-kalb, güçlü kuvvetli, dilîr.' (Kámûs-ı Fârsî, 1. C: 710).

19. mübeccel [şigerf]: 'Seyit, aziz, muhterem, muhteşem.' (Kámûs-ı Fârsî, 19. cüz: 96).

2o. ötlegü [zimç | zimc]: 'Havada çok devrèden bir nevi kerkes kuşu, uşak kapan.' (Kámûs-ı Fârsî, 12. cüz: 6), 'Doğan türünden alıcı bir kuş.' (DİLçíN 1983: 170).

21. oyuk [hose]: 'Bostan korkuluğu, kuşları ve sair hayvanatı korkutmak için tarlalara, bostanlara ve bağlara konulan kukla.' (Kámûs-ı Fârsî, 09. cüz: 69), 'İnsan ya da hayvan şeklini andırır korkuluk.' (DİLÇín 1983: 165). 
22. üzmelik [hefçe]: 'Böğürtlen dikeninin meyvesi.' (Kámûs-ı Fârsî, 07. cüz: 050), 'Sık çalılık.' (Derleme Sözlüğ̈̈, 1974, IX: 3372).

23. puturak [jāj]: 'Tatsız ve fena ot, deve tabanı, teker dikeni dènilen ota dahi bu nam vérilir.' (Kámûsı Fârsî, 01. cüz: 25), 'İnce ve yapışkan dikenli tohumları olan bir çeşit ot.' (Derleme Sözlüğü, 1974, IX: 3493).

24. sấî, berîd, kásıd [āb-gud̄ār]: 'Ulak, tatar, çapar, posta, bir yerden diğer yere mektup nakleden serî‘u 'l-hareke ve su gibi akıp giden postacı.' (Kámûs-ı Fârsî, 1. C: 152).

25. teğelti $[\bar{a} d r u m]$ : 'eyeriñ altına hayvanıñ sırtına örtülen keçe, ki pamuklu gibi teğellenmiş olur, nemed-zîn, berda'a. Top, tüfek, kılıç, harbe, kargı, vesaire gibi âlât-ı harbiñ hey'et-i umûmiyyesi, esbâb1 muhârebe, techîzât-ı harbiyye ve levâzım-ı askeriyye manasına geldiği gibi teğelti dejyecek uzun, sert, büyük bir nevi iğneye ādrum tesmiye olunur.' (Kámûs-ı Fârsî, 1. C: 272), Eyer altına konulan keçe (DİLçìn: 1983: 218 ${ }^{\mathrm{a}}$ ).

26. serkele [hāmişe]: 'Bir nevi şâhterre, saytarac kökü.' (Kámûs-ı Fârsî, o6. cüz: 045), 'Root of plumbago zeylanica.' (REDHOUSE 1890: 1054).

27. sît [āvāz]: 'Şöhret, unvan, nam u şan’ (Kámûs-ı Fârsî, 1. C: 629).

28. tạrıdeveciği [herek]: 'Tanrıdeveciği denilen böcek.' (Kámûs-ı Fârsî, o6. cüz: 095-096), 'Kızlardevesi de denilen çekirgeye benzer bir böcek.' (DİLÇíN 1983: 202).

29. teraşşuh eylemek [şerīden]: 'Su damlamak, sızmak.' (Kámûs-ı Fârsî, 15. cüz: 4).

3o. tünd [ātiş-ser]: 'Yavuz, şiddetli, şedit, pek sert, yaman, kaypak, batş ve hiddetle savlet ve surete malik olan.' (Kámûs-ı Fârsî, 1. C: 214).

31. tuturak [ātiş-ser]: 'Kuru ot, çalı çırpı, çıra, talaş, yonga vesaire gibi ateş yakmağa elvérişli olan mevâd.' (Kámûs-ı Fârsî, I: 196), 'Yonga, talaş.' (Derleme Sözlüğü, 1974, X: 4001).

32. vâlih [āsyūn]: 'Mütehayyir, hayran, şaşmış, ser-gerdan, şaşkın, alık, beht-i hayret içinde kalmış olan' (Kámûs-ı Fârsî, I: 465).

33. yaylağaç [herçekūk]: 'Şemmâme3, küçük kavun şeklinde gayr-1 me'kûl; lakin güzel rayihalı, üzeri pek zarif bir surette hutût-ı tabî‘iyye ile münakkaş bir meyve, ki daima elde tutup istişmam ėderler.' (Kámûs-ı Fârsî, 06. cüz: 87), Limon büyüklüğünde ve kavun gibi güzel kokan bir meyve, şamama. (DİLçİN 1983: 244).

\section{Sonuç}

Dilin dört temel becerisinin sağlıklı bir biçimde gerçekleştirilebilmesi için zengin bir kelime hazinesi olmazsa olmaz şartlardandır. Türkçenin kelime hazinesini zenginleştirebilmek için bugünkü dilimize kaynaklık eden eserler taranmalıdır. Tabii ki eserleri tarayıp bugün işlerliğini yitirmiş olan kelimeleri Türkçe Sözlük'e eklemek tek başına yeterli değildir. Bir kelimenin sözlükte bulunması o kelimenin o

3 şammāmat : Ar. 'fitil, parfüm güzel koku, rayiha, lavanta, esans.', şammām 'koklanan güzel koku, sarı çizgili kavun' (ATAY: $A-T B L: \mathrm{II} / 1140^{\mathrm{b}}$. s.). 
dilin malı olduğu manasına gelmez. Kelimeler sokaktaki insanın dilinde yaşamıyorsa, işlek değilse, o dile ait saylmaz.

TÖMER (Türkçe Öğretme Merkezi)'in yaptığı bir araştırmaya göre Amerika'da ortaöğretim ders kitaplarında 70.400, Almanya ve Japonya'da 44.224, İtalyan okullarında 31.762, Fransa'da 30.193, Suudi Arabistan okullarında 13.579 kelime ve terim kullanılırken Türkiye'deki ders kitaplarında yalnızca 7.260 kelime ve terim kullanılmaktadır (GÖKÇE SULAK 2016: 45).

Çalışmaya kaynaklık eden Kámûs-ı Fârsî adlı Farsça-Osmanlı Türkçesi sözlük günümüzden yaklaşık yüz yıl önce yazılmıştır. Yukarıda listelenen otuz üç kelime Farsça madde başlarının izahında kullanılan kelimelerdir. Bundan yüz yıl önce bir yabancı kelimenin izahında kullandığımız kelimeler ne yazık, ki bugünkü Türkçe Sözlük'te bulunmamaktadır. Türkçeden "bu eski, bu yabancı, bu Arapça, bu Farsça vb." bahanelerle kelimeleri atmak yerine yüzyllar boyunca kullandığımız, artık her şeyiyle bizim olan bütün kelimelerimize sahip çıkarak kelime hazinemizi zenginleştirmeliyiz. Kelime hazinemiz zenginleştirilir, Türkçe Sözlük’te bulunmayan kelimeler sözlüğe eklenir ve işlerliğini yitirmekte olan kelimeler ilk ve orta öğretim ders kitaplarına dâhil edilirse daha geniş düşünen, konuşurken ve yazarken kelime aramayan ve kendi diline hâkimiyeti sayesinde bir yabancı dili de daha kolay öğrenebilen bireyler yetiştirilebileceği muhakkaktır. Dil ile ilgili bu meseleler muhakkak, ki Türkçe eğitimi ile uğraşanların vazifeleridir.

\section{Kaynaklar}

DiLçiN, Cem, Yeni Tarama Sözlüğü, Türk Dil Kurumu Yayınları 503, Ankara 1983.

al-FÎRÛZÂBÂDÎ, Macdu'd-dīn Abū Ṭāhir Muhammad b. Ya'ḳūb: al-Ukyānūsu 'l-Basīt fī Tarcamati 'lKầmūsi 'l-Muhiiṭ: Çeviren: CENĀNĪOĠLU, Aḥmed 'Āṣim, İstanbul I: '-r ²1268, [II]+943 s. II: r-ḳ 21269, [II]+939 s. III: k-v ${ }^{2} 1272$, [II]+975 s.

GÖKÇE SULAK, Sevda, Anlamdaş Kelimelerde Anlam ve Kullanış Farkları, Gece Kitaplığı, Ankara 2016.

Kámûs-ı Fârsî, Türk Dil Kurumu Kütüphanesi, Etüt 8o/1, 93/1, 93/2.

ÖZBAY, Murat. ve MELANLIOĞLU, Deniz. “Türkçe Eğitiminde Kelime Hazinesinin Önemi” Yüzüncü Yıl Üniversitesi Eğitim Fakültesi Dergisi, 5(1), 30-45, Van 2008.

REDHOUSE, James W, Turkish and English Lexicon / Kitâb-ı Ma'ânî-i Lehce. Constantinople 1890.

STEINGASS, Francis Joseph, A Comprehensive Persian-English Dictionary, London 1892.

STEINGASS, Francis Joseph: The Student's Arabic-English Dictionary: London 1884.

TIETZE, Andreas, Wörterbuch der griechischen, slavischen, arabischen und persischen Lehnwörter im Anatolischen Türkisch - Anadolu Türkçesinde Yunanca, İslavca, Arapça ve Farsça Ödünçlemeler Sözlüğü, Derleyen: Mehmet ÖLMEZ, Simurg Türk Dilleri Araştırmaları Dizisi: 26, İstanbul 1999.

TÜRK DİL KURUMU, Türkiye'de Halk Ağzından Derleme Sözlüğü, Atatürk Kültür, Dil ve Tarih Yüksek Kurumu Türk Dil Kurumu Yayınları - Sayı: 211 [/1]-12, Ankara 1963-1982.

YILDIRIM, Ali. ve ŞİMŞEK Hasan. Sosyal Bilimlerde Nitel Araştırma Yöntemleri, Seçkin Yayınları, Ankara 2006.

YILDIZ, Cemal; OKUR, Alpaslan; ARI, Gökhan; YILMAZ, Yakup:, Kuramdan Uygulamaya Türkçe Ögretimi. Pegem Akademi, Ankara 2008. 